\title{
Qol Resistance and Mitochondrial Genetic Structure of Zymoseptoria tritici in Morocco
}

A. Siah, Laboratoire Biotechnologie et Gestion des Agents Pathogènes en agriculture, GIS PhyNoPi, Institut Supérieur d'Agriculture, Université Catholique de Lille, 48 Boulevard Vauban, F-59046 Lille cedex, France; A. Y. Elbekali and A. Ramdani, Institut National de la Recherche Agronomique, BP 578, Meknès, Morocco; P. Reignault, Unité de Chimie Environnementale et Interactions sur le Vivant (UCEIV-EA 4492), GIS PhyNoPi, Université du Littoral Côte d'Opale, BP699, F-62228, Calais cedex, France; S. F. F. Torriani and P. C. Brunner, Institute of Integrative Biology, Plant Pathology, ETH Zurich, CH-8092 Zurich, Switzerland; and P. Halama, Laboratoire Biotechnologie et Gestion des Agents Pathogènes en agriculture, GIS PhyNoPi, Institut Supérieur d'Agriculture, Université Catholique de Lille

\begin{abstract}
Siah, A., Elbekali, A. Y., Ramdani, A., Reignault, P., Torriani, S. F. F., Brunner, P. C., and Halama, P. 2014. QoI resistance and mitochondrial genetic structure of Zymoseptoria tritici in Morocco. Plant Dis. 98:1138-1144.

In total, 230 single-conidial isolates of the fungal wheat pathogen $Z y$ moseptoria tritici (formerly Septoria tritici, teleomorph: Mycosphaerella graminicola) were sampled in Morocco in 2008 and 2010 to assess resistance against quinone outside inhibitors (QoIs), a widely used group of fungicides in wheat pest management. All 134 isolates sampled in 2008 were QoI sensitive. In contrast, 9 of the 96 isolates from the 2010 collection were resistant, suggesting a recent emergence of the resistance. Mitochondrial (mt)DNA-sequence analyses identified four haplotypes among the resistant isolates. Wright's $\mathrm{F}$ statistics $\left(\mathrm{F}_{\mathrm{ST}}\right)$ analyses from mtDNA sequences revealed a shallow population struc-

ture of Z. tritici within Morocco and a substantial asymmetric gene flow from Europe into Morocco. A phylogenetic reconstruction including Moroccan and European isolates clustered the haplotypes regardless of their geographic origin. The four Moroccan QoI-resistant mitochondrial haplotypes clustered in two distinct clades in the tree topology, suggesting at least two independent origins of the resistance. This study reported, for the first time, the occurrence of QoI-resistant genotypes of $Z$. tritici in Morocco. Our findings are consistent with the hypothesis that QoI resistance emerged very recently through parallel genetic adaptation in Morocco, although gene flow from Europe cannot be excluded.
\end{abstract}

Septoria tritici blotch, caused by Zymoseptoria tritici (formerly Septoria tritici, teleomorph: Mycosphaerella graminicola), is currently among the most frequent foliar diseases on both bread wheat (Triticum aestivum) and durum wheat (T. durum) in Morocco and worldwide. Severe disease epidemics can reduce yields by 35 to $50 \%$ (19). Z. tritici undergoes both asexual and sexual reproduction in the field. During asexual reproduction, it produces pycnidiospores that are locally dispersed by rain splash (19). Through sexual reproduction, the pathogen produces ascospores that are dispersed over long distances by wind (15). Although ascospores are responsible for most of the initial infections of wheat in the autumn, they also contribute to disease progression during the growing season because sexual reproduction occurs year-round (15). As a result, the pathogen population is highly diverse, even at the field scale $(22,30)$.

Because host resistance against $Z$. tritici is not completely effective in most wheat cultivars, fungicides are used as a primary method of disease control (11). Methyl benzimidazole carbamates (MBCs) and sterol biosynthesis inhibitor (SBI) fungicides have been the most widely used groups of fungicides to control $Z$. tritici since early and late 1970 s, respectively $(5,16)$. Since their introduction in 1996, strobilurin fungicides, or quinone outside inhibitor (QoI) fungicides, were intensively applied for the management of most agricultural fungal pathogens, including Z. tritici (2). QoI fungicides inhibit mitochondrial respiration in fungi by binding to the Qo binding site of the cytochrome bc1 enzyme complex, thereby blocking electron transfer and halting ATP synthesis (14).

Corresponding author: P. Halama,

E-mail: patrice.halama@isa-lille.fr

Accepted for publication 6 March 2014.

http://dx.doi.org/10.1094/PDIS-10-13-1057-RE

(C) 2014 The American Phytopathological Society
The success of QoI fungicides is due to their higher efficacy and their additional favorable effects on plant physiology (12).

The intensive use of QoI fungicides led to a rapid development of resistant genotypes of $Z$. tritici in Europe (12). As for most other fungi, fungicide resistance in $Z$. tritici is conferred by a point mutation in the mitochondrial cytochrome $b$ (cytb) gene, giving rise to an amino-acid substitution from glycine to alanine at position 143 (G143A) (11,12). This mutation prevents binding of QoI fungicides to the Qo site, hence restoring the ability of the fungus to carry out mitochondrial respiration.

The first resistant isolates of $Z$. tritici were detected in the United Kingdom in 2001 (12), and the frequency rapidly increased across Europe $(7,13,21,26)$. Frequencies of resistant genotypes were higher in the north-European countries such as Belgium, Denmark, Ireland, the United Kingdom, northern France, and northern Germany $(1,13,16,18,21,26)$ than south-European areas such as southern France and southern Germany $(13,16,21)$. This gradient of resistance was thought to be due to differences in the intensity of QoI fungicide use, because lower disease pressure occurs in southern regions $(21,26)$.

Fungicide resistance monitoring is particularly important to ensure effective disease control and is crucial for understanding the distribution, evolution, and the impact of fungicide resistance in the field. Although QoI resistance in Z. tritici is currently widespread throughout Europe, recent investigations revealed an absence of fungicide resistance in Africa $(4,24)$. To date, there is no information available regarding QoI resistance in Morocco, despite the use of QoI fungicides to control wheat pathogens, including $Z$. tritici (10). The main objectives of this work were (i) to investigate whether QoI resistance occurs in the Moroccan population of $Z$. tritici and, if present, (ii) whether resistance emerged locally or was introduced from Europe.

\section{Materials and Methods}

Fungal sampling and isolation. A set of 230 single-conidial isolates of $Z$. tritici were sampled from six distinct wheat-produc- 
ing locations in Morocco (Table 1). In all, 134 isolates were first collected in 2008 from Chaouia, Gharb-Chrarda, Meknes-Tafilalet, and Tadla-Azilal. In 2010, 96 additional isolates were collected from these regions and two new locations, Doukkala-Abda and Fes-Boulmane (Table 1). Each set of isolates sampled from each location at the same time point will hereafter be referred to as a subpopulation. The isolates were collected according to the protocol described by Siah et al. (23) from nonfungicide-treated and naturally infected wheat plants. All isolates were grown on potato dextrose agar (PDA) medium for 2 weeks and stored at $-80^{\circ} \mathrm{C}$ for further analyses.

DNA extraction. DNA was extracted from 2-week-old PDAgrown cultures according to Siah et al. (21), with modifications. Briefly, approximately $50 \mathrm{mg}$ of cirrhus were harvested from a PDA-grown culture of each isolate and transferred into a $1.5-\mathrm{ml}$ microcentrifuge tube. After the addition of $200 \mu \mathrm{l}$ of sterile distilled water, each tube was vortexed and sonicated (Deltasonic) for $20 \mathrm{~min}$. Phenolchloroform $(400 \mu \mathrm{l})$ was added to each tube, vortexed, and centrifuged for $5 \mathrm{~min}$ at $13,000 \mathrm{rpm}$ and $4^{\circ} \mathrm{C}$ (Hettich, Zentrifugen). The aqueous phase was collected and transferred into a clean microcentrifuge tube. After addition of $300 \mu \mathrm{l}$ of chloroform, the tubes were vortexed and centrifuged at 13,000 rpm and $4^{\circ} \mathrm{C}$ for $3 \mathrm{~min}$. This operation was repeated twice. The aqueous phase was transferred to new clean tubes. Total DNA was precipitated overnight at $-20^{\circ} \mathrm{C}$ after the addition of $10 \mu \mathrm{l}$ of $\mathrm{NaCl}(5 \mathrm{M})$ and $500 \mu \mathrm{l}$ of absolute ethanol. After centrifugation for $30 \mathrm{~min}$ at $14,000 \mathrm{rpm}$ and $4^{\circ} \mathrm{C}$, the pellets were washed with $70 \%$ ethanol. The tubes were then centrifuged for $15 \mathrm{~min}$ at $14,000 \mathrm{rpm}$ and $4{ }^{\circ} \mathrm{C}$ before they were dried for $20 \mathrm{~min}$ in desiccators. DNAs were solubilized in $40 \mu \mathrm{l}$ of sterile distilled water for $20 \mathrm{~min}$ at $37^{\circ} \mathrm{C}$ and the concentrations were determined at $260 \mathrm{~nm}$ using a UV light spectrophotometer (UV Light). The tubes containing DNAs were then stored at $-20^{\circ} \mathrm{C}$ for further investigations.

Polymerase chain reaction mismatch to determine G143A substitution. Sensitivity to QoI fungicides among the isolates was determined using a mismatch amplification mutation assay on part of the cytb gene $(21,28)$. Primers were designed with a mismatch on the penultimate nucleotide of the $3^{\prime}$ end of the forward primer, in which the ultimate nucleotide was at the point mutation position of codon 143. The primer set used to amplify a 639-bp DNA fragment in sensitive isolates was sense primer StrobSNP2fwd $\left(5^{\prime}\right.$ CTTATGGTCAAATGTCTTTATGATG-3', nucleotides 404 to 428 of the $c y t b$ gene sequence), with a mismatch of $\mathrm{T}$ instead of $\mathrm{G}$ at nucleotide position 427, and antisense primer StrobSNP1rvs ( $5^{\prime}$ GGTGACTCAACGTGATAGC-3', nucleotides 1,024 to 1,043 of $c y t b)$. The primer set used to amplify a 302-bp DNA fragment in resistant isolates was antisense primer StrobSNPrcF7 (5'-CAA TAAGTTAGTTATAACTGTTGCGG-3', nucleotides 428 to 453 of the $c y t b$ gene sequence), with a mismatch of $\mathrm{T}$ instead of $\mathrm{G}$ at nucleotide 429, and sense primer StrobSNPrcR1 (5'-CTATGC ATTATAACCCTAGCGT-3', nucleotides 152 to 173). This resulted in a single-nucleotide mismatch on the sequence of the sensitive isolates and a double-nucleotide mismatch on the sequence of the resistant isolates, and vice versa for each primer set. Polymerase chain reaction (PCR) reactions and PCR-thermal cycling conditions were performed according to Siah et al. (21). PCR products were separated by electrophoresis on $1.5 \%$ agarose gels run at 100 $\mathrm{V}$ for $45 \mathrm{~min}$. After ethidium bromide staining and visualizing under UV light, images were captured with a digital camera (Clara Vision) and scored manually.

Phenotypical evaluation of fungicide resistance. Phenotypic assays of QoI sensitivity were performed for 18 Moroccan isolates (9 isolates with the G143 allele and 9 isolates with the A143 allele) in clear and sterile flat-bottomed polystyrene microplates (Iwaki, Asahi techno glass) with eight rows of 12 wells. The QoI fungicide azoxystrobin (Sigma-Aldrich) was added to the medium at $50^{\circ} \mathrm{C}$ after autoclaving and after suspension in $0.5 \mathrm{ml}$ of dimethyl sulfoxide (DMSO) (Merck). Final concentration of DMSO in the medium, including controls without fungicide, did not exceed 0.5 $\mathrm{ml} / \mathrm{liter}$ of medium. Plate wells were filled with $150 \mu \mathrm{l}$ of liquid glucose peptone medium (dextrose [VWR] at $14.3 \mathrm{~g} / \mathrm{liter}$, bactopeptone [Difco Laboratories] at $7.1 \mathrm{~g} / \mathrm{liter}$, and yeast extract [Merck] at $1.4 \mathrm{~g} /$ liter) amended with azoxystrobin at concentrations $0.006,0.025,0.1,0.4,1.6,6.3,25$, and $100 \mathrm{ppm}$ (final concentrations in $200 \mu \mathrm{l}$ of medium). Aliquots of $50 \mu \mathrm{l}$ of $2 \times 10^{5}$ spores/ml, which were obtained by washing a 7 day-old PDA fungal culture grown at $20^{\circ} \mathrm{C}$ with sterile distilled water, were added to the plate wells. Eight wells were used as replicates for each condition. Controls without fungus and without fungicide as well as medium with fungus and without fungicide were used for each isolate. After incubation for 6 days at $20^{\circ} \mathrm{C}$ in darkness and under horizontal shaking at $140 \mathrm{rpm}$, fungal growth was measured in a plate reader (MRX; Dynex Technologies) at $405 \mathrm{~nm}$. The fungicide sensitivity of each isolate was determined as half maximal inhibitory concentration $\left(\mathrm{IC}_{50}\right)$ calculated using a dose-response relationship and nonlinear regression model according to the GraphPad Prism 5 software (Hearne Scientific Software). The bioassay was replicated twice and similar $\mathrm{IC}_{50}$ values were obtained with both replications for each isolate.

Mitochondrial DNA-sequence amplification and sequencing. Three mitochondrial (mt)DNA sequences, named $M g 1, M g 2$, and $M g 3$ (27), were examined to estimate the mtDNA diversity of $Z$. tritici in Morocco and to reconstruct the phylogenetic relationship among Moroccan and European mtDNA haplotypes. These loci are located in different regions of the mtDNA and display different degrees of polymorphism in the comparison between the STBB1 and IPO323 isolates (27). These three sequences were amplified for 152 isolates: 100 isolates from Morocco (50 from each year of collection) and 52 reference isolates from Europe (26). Primer sets used for the amplifications were $\mathrm{Mg} 1 \mathrm{~F}$ (5'-CCGGTCCCTCTA ATAGTTCTGG-3') and Mg1R (5'-TAATCCGCCATTACTTCT CAGG-3'), Mg2F (5'-GGTTCCAATGGGTTTAATGCTA-3') and Mg2R (5'-TGGGTGTAGCTAGAAACCCTTC-3'), and Mg3F (5'AAGCTACGCCTATGGCTAACAC-3') and Mg3R (5'-AGGTAA GACGCACGCATTTC-3'). PCR reactions were performed in a 50$\mu \mathrm{l}$ volume containing $0.1 \mu \mathrm{l}(20 \mu \mathrm{M})$ of each primer, $4 \mu \mathrm{l}(2.5 \mathrm{mM})$ of dNTPs, $5 \mu \mathrm{l}$ of $10 \times$ reaction buffer, $8 \mu \mathrm{l}(25 \mathrm{mM})$ of $\mathrm{MgCl}_{2}, 0.25$ $\mathrm{U}$ of Taq polymerase (Ampli Taq Gold, Applied Biosystem, Roche), and $5 \mu \mathrm{l}$ of fungal DNA (1 ng/ $\mu \mathrm{l}$ final DNA concentration). The amplifications were carried out using a Peltier thermal cycler (MJ Research) under the following temperature program: initial denaturation at $94^{\circ} \mathrm{C}$ for $10 \mathrm{~min}$; followed by 40 cycles of $94^{\circ} \mathrm{C}$ for $1 \mathrm{~min}, 56^{\circ} \mathrm{C}$ for $30 \mathrm{~s}$, and $72^{\circ} \mathrm{C}$ for $1 \mathrm{~min}$; with a final extension at $72^{\circ} \mathrm{C}$ for $10 \mathrm{~min}$. The PCR products were sequenced using the primers $\mathrm{Mg} 1 \mathrm{~F}, \mathrm{Mg} 2 \mathrm{~F}$, and $\mathrm{Mg} 3 \mathrm{R}$, generating a total of 733 concatenated nucleotides. Sequencing reactions were performed as described previously by Torriani et al. (27) for STBB1. DNA sequence alignments were done using the BioEdit software (http://www.mbio.ncsu.edu/BioEdit/bioedit.html).

Genetic data analyses. Standard population genetic parameters were estimated using DnaSP 5.10 (17). Hierarchical analysis of molecular variance (AMOVA) implemented in ARLEQUIN 3.5 (9) was used to determine the degree of genetic differentiation at three levels: (i) within subpopulations, (iii) among subpopulations within 2008 and 2010 populations, and (iii) between 2008 and 2010 populations. ARLEQUIN 3.5 was also used to assess Wright's F statistics $\left(\mathrm{F}_{\mathrm{ST}}\right)$ for population differentiation for all population pairs.

Table 1. Number and origin of Moroccan Zymoseptoria tritici isolates used in this study

\begin{tabular}{llccc}
\hline & & \multicolumn{2}{c}{ Number of isolates } & \\
\cline { 3 - 4 } Location & Wheat species & $\mathbf{2 0 0 8}$ & $\mathbf{2 0 1 0}$ & Total \\
\hline Meknes-Tafilalet & Triticum aestivum & 45 & 22 & 67 \\
Gharb-Chrarda & T. aestivum & 55 & 6 & 61 \\
Tadla-Azilal & T. aestivum & 11 & 27 & 37 \\
Chaouia & T. aestivum & 23 & 8 & 37 \\
Doukkala-Abda & T. durum & $\ldots$ & 22 & 17 \\
Fes-Boulmane & T. aestivum & $\ldots$ & 12 & 11 \\
Total & .. & 134 & 96 & 230 \\
\hline
\end{tabular}


Significance of differentiation $(P<0.05)$ was estimated with the implemented Markov chain-based exact test of population differentiation.

Maximum likelihood (ML) phylogenetic trees were constructed using MEGA version 5 (25). The ML analyses were performed using the Tamura 3-parameter model with a discrete $\gamma$ with five rate categories. The model search algorithm implemented in MEGA selected this model as having the lowest Bayesian Information Criterion score, which is considered to describe the nucleotide substitution pattern the best. All positions with less than $70 \%$ site coverage were eliminated. Statistical node support was estimated using 500 bootstrap replications.

Long-term migration rates between Europe and Morocco were estimated using the ML approach implemented in MIGRATE (3).
Based on the $\mathrm{F}_{\mathrm{ST}}$ analyses that suggested low genetic differentiation between populations sampled at different time points (see results below), all populations from Morocco were pooled. The starting values for the migration rates were estimates based on pairwise $\mathrm{F}_{\mathrm{ST}}$. Markov chain settings were 15 short chains, 3 long chains with a burn-in of 10,000 trees, and averaging over long chains. The analysis was repeated three times to ensure convergence of parameter estimates.

\section{Results}

Frequency and distribution of sensitive and resistant alleles. Sensitive and resistant isolates generated the expected single fragments of 639 and $302 \mathrm{bp}$, respectively (Fig. 1). All isolates sampled in 2008 had the 639-bp allele associated with sensitivity (Fig. 2).
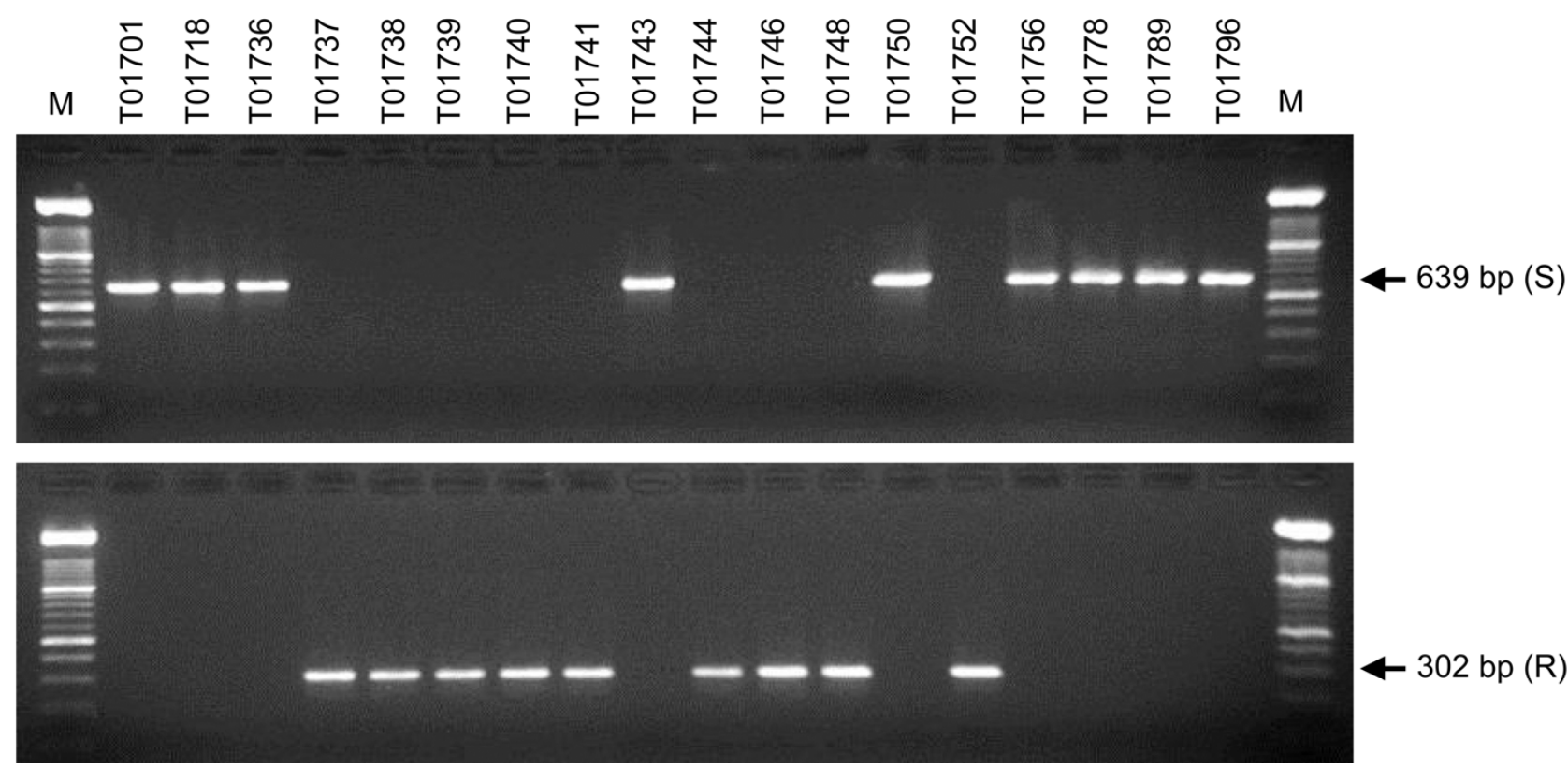

Fig. 1. Mismatch amplification mutation assay on a part of the cytochrome $b$ gene to determine $G 143$ or A143 allele in 18 Zymoseptoria tritici isolates from Morocco. Sensitive isolates carrying G143 allele generated an amplicon of $639 \mathrm{bp}$. Resistant isolates carrying A143 allele generated an amplicon of $302 \mathrm{bp}$. Lane M = molecular size standard XIV (100-bp ladder).
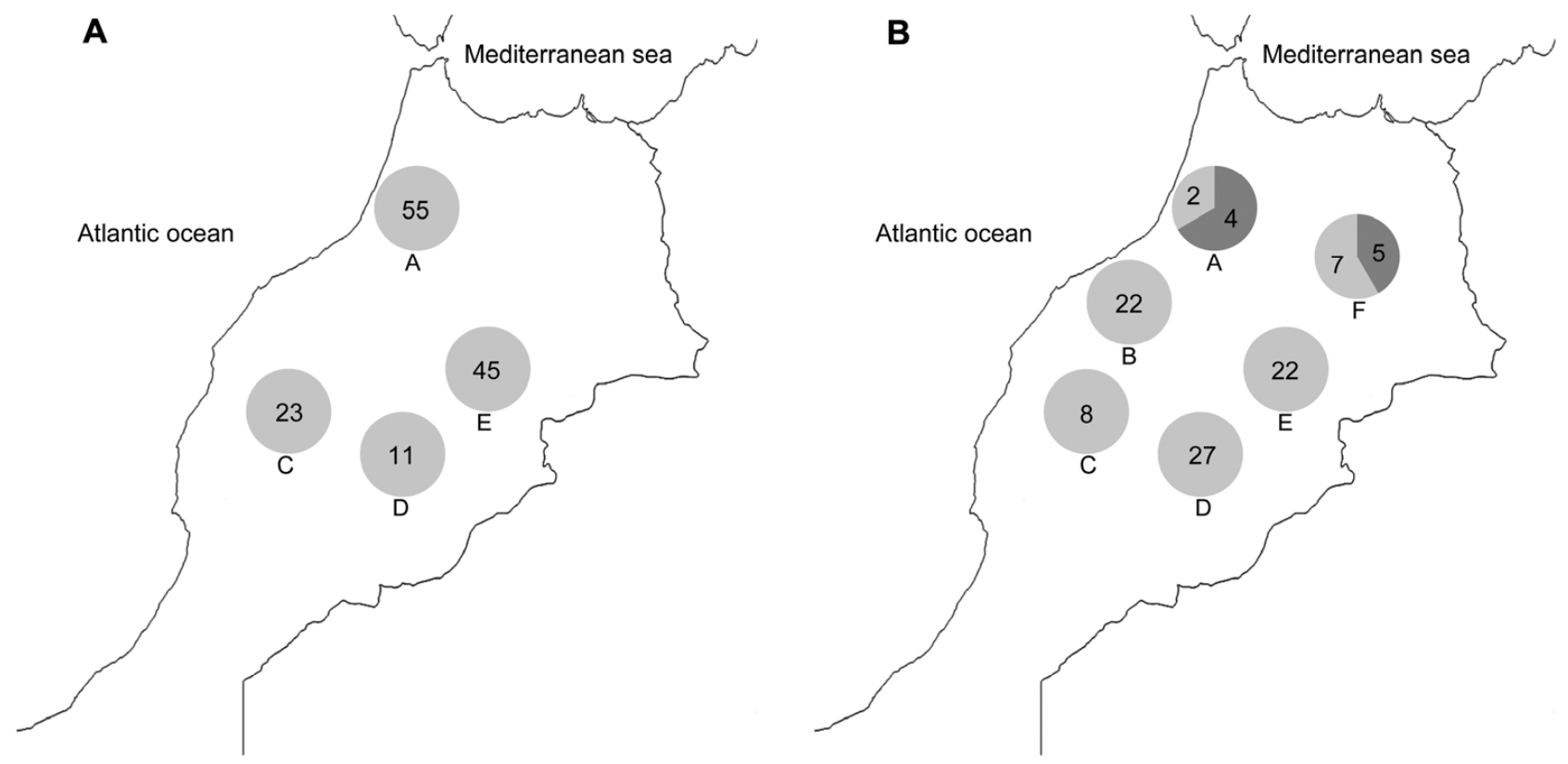

Fig. 2. Map of northern Morocco showing the frequencies of quinone outside inhibitor (Qol)-sensitive and Qol-resistant Zymoseptoria tritici isolates within the locations

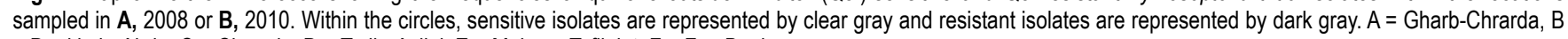
= Doukkala-Abda, $\mathrm{C}=$ Chaouia, $\mathrm{D}=$ Tadla-Azilal, $\mathrm{E}=$ Meknes-Tafilalet, $\mathrm{F}=$ Fes-Boulmane. 
However, nine isolates (9.4\%) sampled in 2010 (four from GharbChrarda and five from Fes-Boulmane) had the A143 allele that is associated with resistance (Figs. 1 and 2). The resistance of these isolates was confirmed phenotypically with the microplate bioassay. The nine sensitive isolates used as controls displayed very low $\mathrm{IC}_{50}$ values compared with the nine resistant isolates, resulting in a sharp bimodal distribution pattern for $\mathrm{IC}_{50}$ values (Table 2). $\mathrm{IC}_{50}$ values were 0.003 to $0.15 \mathrm{ppm}$ for sensitive isolates and 7.15 to $>100 \mathrm{ppm}$ for resistant isolates.

Mitochondrial genetic structure. The concatenated mtDNA sequences (733 bp) allowed us to identify 28 distinct haplotypes among the 100 Moroccan isolates analyzed (Table 3). The four

Table 2. Half maximal inhibitory concentrations $\left(\mathrm{IC}_{50}\right)$ obtained with azoxystrobin for 18 Moroccan Zymoseptoria tritici isolates using the

\begin{tabular}{llccc}
\hline Isolate & \multicolumn{1}{c}{ Location } & Allele $^{\mathbf{a}}$ & $\begin{array}{c}\text { IC }_{\mathbf{5 0}} \\
(\mathbf{m g} \text { /liter })\end{array}$ & S or R $^{\mathbf{b}}$ \\
\hline T01743 & Fes-Boulmane & $\mathrm{G} 143$ & 0.003 & $\mathrm{~S}$ \\
T01718 & Meknes-Tafilalet & $\mathrm{G} 143$ & 0.01 & $\mathrm{~S}$ \\
T01796 & Tadla-Azilal & $\mathrm{G} 143$ & 0.02 & $\mathrm{~S}$ \\
T01778 & Chaouia & $\mathrm{G} 143$ & 0.02 & $\mathrm{~S}$ \\
T01756 & Fes-Boulmane & $\mathrm{G} 143$ & 0.04 & $\mathrm{~S}$ \\
T01789 & Tadla-Azilal & $\mathrm{G} 143$ & 0.09 & $\mathrm{~S}$ \\
T01701 & Tadla-Azilal & $\mathrm{G} 143$ & 0.15 & $\mathrm{~S}$ \\
T01750 & Fes-Boulmane & $\mathrm{G} 143$ & 0.15 & $\mathrm{~S}$ \\
T01736 & Gharb-Chrarda & $\mathrm{G} 143$ & 0.15 & $\mathrm{~S}$ \\
T01744 & Fes-Boulmane & $\mathrm{A} 143$ & 7.15 & $\mathrm{R}$ \\
T01748 & Fes-Boulmane & $\mathrm{A} 143$ & 12.99 & $\mathrm{R}$ \\
T01746 & Fes-Boulmane & $\mathrm{A} 143$ & 20.74 & $\mathrm{R}$ \\
T01741 & Fes-Boulmane & $\mathrm{A} 143$ & $>100$ & $\mathrm{R}$ \\
T01752 & Fes-Boulmane & $\mathrm{A} 143$ & $>100$ & $\mathrm{R}$ \\
T01737 & Gharb-Chrarda & $\mathrm{A} 143$ & $>100$ & $\mathrm{R}$ \\
T01738 & Gharb-Chrarda & $\mathrm{A} 143$ & $>100$ & $\mathrm{R}$ \\
T01739 & Gharb-Chrarda & $\mathrm{A} 143$ & $>100$ & $\mathrm{R}$ \\
T01740 & Gharb-Chrarda & $\mathrm{A} 143$ & $>100$ & $\mathrm{R}$ \\
\hline
\end{tabular}

a Presence of G143 or A143 allele.

${ }^{\mathrm{b}}$ Sensitive (S) or resistant (R). microplate assay

resistant isolates from Gharb-Chrarda shared one haplotype, while the five resistant isolates from Fes-Boulmane had four haplotypes. The resistant haplotype M 4 was found both in Gharb-Chrarda and Fes-Boulmane (Table 4). Although very similar to each other, no Moroccan haplotype was identical to any of the European haplotypes previously described by Torriani et al. (26). There was no significant difference in haplotype diversity between the 2008 and the 2010 collections (Table 3 ).

Pairwise $\mathrm{F}_{\mathrm{ST}}$ comparisons among populations revealed very low or nonsignificant genetic differentiation between most Moroccan subpopulations (Table 5), with the exception of the 2010 TadlaAzilal subpopulation that was significantly different at $P=0.05$ (Table 5). AMOVA analyses supported the low mtDNA-based population structure found in Morocco and showed that $96.3 \%$ of genetic variation could be explained by differences among indi-

Table 3. Population genetic parameters of 10 Moroccan Zymoseptoria tritici subpopulations sampled at two time points ${ }^{\mathrm{a}}$

\begin{tabular}{|c|c|c|c|c|}
\hline Year, location & $n$ & $\mathbf{S}$ & $\mathbf{H}$ & Hd \\
\hline \multicolumn{5}{|l|}{2008} \\
\hline Gharb-Chrarda & 22 & 7 & 8 & 0.84 \\
\hline Meknes-Tafilalet & 19 & 19 & 12 & 0.94 \\
\hline Chaouia & 7 & 11 & 6 & 0.95 \\
\hline Tadla-Azilal & 2 & 1 & 2 & 1.00 \\
\hline All 2008 & 50 & 21 & 20 & 0.90 \\
\hline \multicolumn{5}{|l|}{2010} \\
\hline Gharb-Chrarda & 5 & 4 & 2 & 0.40 \\
\hline Meknes-Tafilalet & 9 & 5 & 3 & 0.67 \\
\hline Chaouia & 8 & 12 & 5 & 0.86 \\
\hline Tadla-Azilal & 7 & 7 & 3 & 0.76 \\
\hline Doukkala-Abda & 7 & 3 & 3 & 0.76 \\
\hline Fes-Boulmane & 14 & 16 & 9 & 0.91 \\
\hline All 2010 & 50 & 17 & 14 & 0.86 \\
\hline Total & 100 & 21 & 28 & 0.88 \\
\hline
\end{tabular}

Table 4. Geographic and temporal distribution of mtDNA haplotypes among 10 Moroccan Zymoseptoria tritici subpopulations sampled at two time points ${ }^{\mathrm{a}}$

\begin{tabular}{|c|c|c|c|c|c|c|c|c|c|c|}
\hline \multirow[b]{2}{*}{ Haplotype } & \multicolumn{4}{|c|}{2008} & \multicolumn{6}{|c|}{2010} \\
\hline & $\begin{array}{l}\text { Gharb- } \\
\text { Chrarda }\end{array}$ & $\begin{array}{l}\text { Meknes- } \\
\text { Tafilalet }\end{array}$ & Chaouia & $\begin{array}{l}\text { Tadla- } \\
\text { Azilal }\end{array}$ & $\begin{array}{l}\text { Gharb- } \\
\text { Chrarda }\end{array}$ & $\begin{array}{l}\text { Meknes- } \\
\text { Tafilalet }\end{array}$ & Chaouia & $\begin{array}{l}\text { Tadla- } \\
\text { Azilal }\end{array}$ & $\begin{array}{c}\text { Doukkala- } \\
\text { Abda }\end{array}$ & $\begin{array}{c}\text { Fes- } \\
\text { Boulmane }\end{array}$ \\
\hline M 1 & 2 & - & - & - & - & - & - & - & - & - \\
\hline M 2 & 3 & - & - & - & - & - & - & - & - & $1 \mathrm{R}$ \\
\hline M 3 & 2 & - & 1 & 1 & - & - & - & - & 3 & 1 \\
\hline M 4 & 8 & 4 & 1 & 1 & $4 \mathrm{R}$ & 5 & - & 2 & - & $3+1 R$ \\
\hline M 5 & 3 & 1 & 1 & - & - & 2 & 3 & - & 2 & 2 \\
\hline M 6 & 2 & - & - & - & - & - & - & - & - & - \\
\hline M 7 & 1 & - & - & - & - & - & - & - & - & - \\
\hline M 8 & 1 & - & - & - & - & - & 2 & - & 2 & - \\
\hline M 9 & - & 1 & - & - & - & - & - & - & - & - \\
\hline M 10 & - & 1 & - & - & - & - & - & - & - & - \\
\hline M 11 & - & 1 & 1 & - & - & - & 1 & - & - & 1 \\
\hline M 12 & - & 2 & - & - & - & - & - & - & - & - \\
\hline M 13 & - & 2 & - & - & - & - & - & - & - & - \\
\hline M 14 & - & 2 & - & - & - & - & - & - & - & - \\
\hline M 15 & - & 1 & - & - & - & - & - & - & - & - \\
\hline M 16 & - & 1 & - & - & - & - & - & - & - & - \\
\hline M 17 & - & 1 & - & - & - & - & - & - & - & - \\
\hline M 18 & - & 2 & - & - & - & - & - & - & - & - \\
\hline M 19 & - & - & 2 & - & - & - & - & - & - & - \\
\hline M 20 & - & - & 1 & - & - & - & - & - & - & - \\
\hline M 21 & - & - & - & - & - & - & - & 2 & - & - \\
\hline M 22 & - & - & - & - & 1 & 2 & - & - & - & - \\
\hline M 23 & - & - & - & - & - & - & - & - & - & $1 \mathrm{R}$ \\
\hline M 24 & - & - & - & - & - & - & - & - & - & $2 \mathrm{R}$ \\
\hline M 25 & - & - & - & - & - & - & - & - & - & 1 \\
\hline M 26 & - & - & - & - & - & - & - & - & - & 1 \\
\hline M 27 & - & - & - & - & - & - & 1 & - & - & - \\
\hline M 28 & - & - & - & - & - & - & 1 & 3 & - & - \\
\hline
\end{tabular}

a "R" indicates quinone outside inhibitor-resistant isolates. 
viduals within subpopulations and only $4.8 \%$ by differences among subpopulations within 2008 and 2010 populations (Table 6). There was no variation attributed to differences between the 2008 and 2010 populations (Table 6 ).

Geographical origin of resistant isolates. The concatenated nucleotide data from three mitochondrial loci were used to reconstruct the phylogenetic relationships among the Moroccan and European haplotypes of $Z$. tritici. The reconstructed ML tree clustered the haplotypes regardless of their geographic origin (e.g., European and Moroccan haplotypes did not cluster in distinct clades; Fig. 3). The four mitochondrial haplotypes included QoIresistant isolates clustered in different clades. M 2 and M 23 are closely related and belong to the same clade, which was different from the one containing M 4 and M 24. These results indicate that the resistant allele originated in at least two unrelated genetic backgrounds. Interestingly, historical migration rates based on the ML estimates (MLEs) implemented in MIGRATE-N revealed a substantial asymmetric gene flow from Europe into Morocco (MLE = $84.29 ; 5$ th to 95 th percentile range $=28.73$ to 196.26 ). In contrast, no significant gene flow was inferred in the opposite direction $(\mathrm{MLE}=0 ; 5$ th to 95 th percentile range $=0.00$ to 0.10$)$.

\section{Discussion}

This is the first detection of QoI-resistant genotypes of Z. tritici in Africa. Boukef et al. (4) did not report any resistant A143 allele in a population of 357 Z. tritici isolates collected in Tunisia in 2007 and 2008. Likewise, Stammler et al. (24) analyzed phenotypically 52 Tunisian isolates sampled in 2010 and concluded that all isolates were sensitive to the QoI fungicide pyraclostrobin. The status of Z. tritici QoI resistance in Africa, including Morocco, differs strongly from the present situation in Western Europe, where high frequencies of resistance have been detected in most countries (http://www.frac.info/work/FRAC_QoI_Minutes2009Final.pdf).

Such a difference is most likely explained by the lower fungicide usage in Morocco compared with Europe, where fungicide applications are more common $(6,10)$. Recent research revealed that QoI resistance in Z. tritici is also widespread in Eastern Europe, especially in the Czech Republic, where a rapid increase in resistance was observed between 2005 and 2011, coinciding with the widespread application of QoI fungicides (7).

Two nonexclusive hypotheses were proposed to explain the rapid spread of QoI resistance over Europe: (i) the G143A mutation occurred only once or at a very low local level and was subsequently distributed to other regions by migration of resistant individuals, and (ii) the G143A mutation occurred independently in several different mtDNA haplotypes or geographic regions. Torriani et al. (26) showed that the resistance in Europe emerged in at least four distinct genetic backgrounds and that the frequency of the resistant allele rapidly increased because of strong fungicide selection. Patterns of migrations were eastward, presumably through wind dispersal of ascospores (26). No QoI resistance has been reported in Asia, such as in Iran, where only the wild-type allele G143 was found in 89 Z. tritici isolates sampled from five provinces (20). More recently, Estep et al. (8) analyzed two fungal collections from two locations in western Oregon in the United States and found frequencies of $9.5 \%(16 / 169)$ and $83.4 \%$ $(146 / 175)$ of resistant isolates in the two collections, respectively, hence reporting for the first time the occurrence of QoI-resistant genotypes of $Z$. tritici in North America.

The absence of resistance in our 2008 collection and its detection in the 2010 collection suggests that QoI resistance arose recently in Moroccan populations of Z. tritici. On the other hand, the highlighted long-term gene flow from Europe into Morocco and the lack of geographic substructure in the phylogenetic reconstruction support the introduction of resistant haplotypes in Morocco via wind-dispersed ascospores from Europe. This conclusion might additionally be supported by the geographical origin of the resistant isolates that were found only in the northernmost locations, Gharb-Chrarda and Fes-Boulmane, close to Europe (Fig. 2). Thus, the emergence of resistance in Morocco could be the result of ascospore dispersal from southern France, where frequencies of QoI resistance are currently high (6). However, the MIGRATE analyses estimate long-term (i.e., past) gene flow. Hence, the gene flow detected from Europe into Morocco and the lack of geographic substructure in the phylogenetic tree are more likely the signatures of ancient exchanges, retained by the extremely conserved mtDNA of $Z$. tritici $(27,29)$. Indeed, the observation that there were no shared haplotypes between Morocco and Europe suggests the lack of recent gene flow, negating the hypothesis of recent QoI resistance acquisition from Europe. Instead, the occurrence of the QoI-resistance mutation in different genetic backgrounds suggests an independent origin of the resistance in Morocco, which likely arose very recently at least twice. Additional analyses, for instance with highly variable microsatellite markers,

Table 5. Population differentiation measured by $\mathrm{F}_{\mathrm{ST}}$ (above the diagonal) among 10 Moroccan Zymoseptoria tritici subpopulations $^{\mathrm{a}}$

\begin{tabular}{|c|c|c|c|c|c|c|c|c|c|c|}
\hline \multirow[b]{2}{*}{ Subpopulations } & \multicolumn{4}{|c|}{ Morocco 2008} & \multicolumn{6}{|c|}{ Morocco 2010} \\
\hline & $\begin{array}{l}\text { Gharb- } \\
\text { Chrarda }\end{array}$ & $\begin{array}{l}\text { Meknes- } \\
\text { Tafilalet }\end{array}$ & Chaouia & $\begin{array}{l}\text { Tadla- } \\
\text { Azilal }\end{array}$ & $\begin{array}{l}\text { Meknes- } \\
\text { Tafilalet }\end{array}$ & $\begin{array}{l}\text { Gharb- } \\
\text { Chrarda }\end{array}$ & $\begin{array}{c}\text { Fes- } \\
\text { Boulmane }\end{array}$ & $\begin{array}{c}\text { Doukkala- } \\
\text { Abda }\end{array}$ & Chaouia & $\begin{array}{l}\text { Tadla- } \\
\text { Azilal }\end{array}$ \\
\hline \multicolumn{11}{|l|}{2008} \\
\hline Gharb-Chrarda & $\ldots$ & 0.01 & 0.15 & 0.00 & 0.05 & 0.00 & 0.016 & 0.00 & 0.00 & 0.39 \\
\hline Meknes-Tafilalet & - & $\ldots$ & 0.00 & 0.00 & 0.00 & 0.00 & 0.00 & 0.03 & 0.00 & 0.17 \\
\hline Chaouia & + & - & $\ldots$ & 0.00 & 0.02 & 0.00 & 0.08 & 0.18 & 0.02 & 0.17 \\
\hline Tadla-Azilal & - & - & - & $\ldots$ & 0.00 & 0.00 & 0.00 & 0.00 & 0.00 & 0.29 \\
\hline \multicolumn{11}{|l|}{2010} \\
\hline Meknes-Tafilalet & - & - & - & - & $\ldots$ & 0.00 & 0.00 & 0.09 & 0.00 & 0.32 \\
\hline Gharb-Chrarda & - & - & - & - & - & $\ldots$ & 0.00 & 0.07 & 0.00 & 0.31 \\
\hline Fes-Boulmane & - & - & - & - & - & - & $\ldots$ & 0.08 & 0.00 & 0.28 \\
\hline Doukkala-Abda & - & - & - & - & - & - & - & $\ldots$ & 0.03 & 0.52 \\
\hline Chaouia & - & - & - & - & - & - & - & - & $\ldots$ & 0.24 \\
\hline Tadla-Azilal & + & + & + & - & + & + & + & + & + & $\ldots$ \\
\hline
\end{tabular}

a Significance at $P<0.05$ (below diagonal) was assessed using the exact test of population differentiation implemented in the program ARLEQUIN 3.5.

Table 6. Hierarchic analysis of molecular variance at three levels in the Moroccan Zymoseptoria tritici populations ${ }^{\mathrm{a}}$

\begin{tabular}{lcccc}
\hline Source of variation & df & Sum of squares & Variance components & Variation $(\%)$ \\
\hline Between 2008 and 2010 populations & 1 & 0.72 & $0.00 \mathrm{Va}$ & 0.0 \\
Among subpopulations within populations & 8 & 7.54 & $0.03 \mathrm{Vb}$ & 4.8 \\
Within subpopulations & 90 & 58.25 & $0.65 \mathrm{Vc}$ & 0.67 \\
Total & 99 & 66.50 & 0.3 & $\ldots$ \\
\hline
\end{tabular}

a Populations are pooled subpopulations sampled in 2008 or 2010, respectively. Subpopulations are set of isolates sampled in the corresponding locations. 


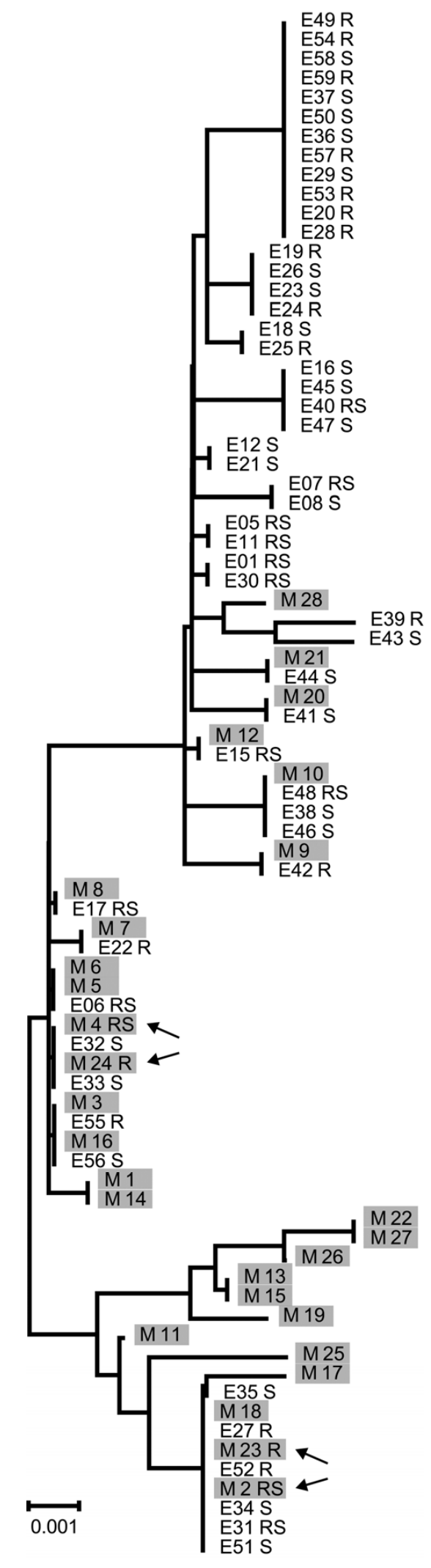

Fig. 3. Molecular phylogenetic analysis by maximum likelihood method based on the Tamura 3-parameter model. The bootstrap consensus tree inferred from 500 replicates is taken to represent the evolutionary relationship of 80 mitochondrial DNA Zymoseptoria tritici haplotypes. Haplotypes abbreviated as "E" are European haplotypes, described in a previous study (26). Haplotypes abbreviated as " $\mathrm{M}$ " and highlighted in gray are Moroccan haplotypes identified in this study. Suffixes "R" and "S" identify haplotypes found among quinone outside inhibitor (Qol)-resistant and Qol-sensitive isolates, respectively. Branches corresponding to partitions reproduced in less than $50 \%$ bootstrap replicates are collapsed. The tree is drawn to scale, with branch lengths measured in the number of substitutions per site. Arrows indicate the position of the four resistant Moroccan haplotypes. would allow us to assess levels of recent gene flow (i.e., a few generations back) and to calculate probabilities as to whether the resistant Moroccan isolates arose locally.

In conclusion, this study highlighted the presence of QoI-resistant genotypes of $Z$. tritici in Morocco. However, the resistance mutation is at a low frequency and restricted locally, indicative of a recent emergence and early stage of resistance development. Therefore, appropriate QoI fungicide management is of utmost importance to preserve a low to moderate distribution of the resistance. Under these assumptions, we propose to use QoI fungicides in mixtures or in alternation with other fungicide classes to avoid further intraspecific parallel genetic adaptation of $Z$. tritici to QoI fungicides and, therefore, putatively reduce the spread of the resistance across Morocco and Northern Africa.

\section{Acknowledgments}

This research was supported by the Programme de Recherche Agronomique pour le Développement project and by an intern financial support from ISA-Lille and ETH-Zurich.

\section{Literature Cited}

1. Amand, O., Calay, F., Coquillart, L., Legat, T., Bodson, B., Moreau, J. M., and Maraite, H. 2003. First detection of resistance to QoI fungicides in Mycosphaerella graminicola on winter wheat in Belgium. Commun. Agric. Appl. Biol. Sci. 68:519-531

2. Bartlett, D. W., Clough, J. M., Godwin, J. R., Hall, A. A., Hamer, M., and Parr-Dobrzanski, B. 2002. The strobilurin fungicides. Pest Manage. Sci. 58:649-662.

3. Beerli, P., and Palczewski, M. 2010. Unified framework to evaluate panmixia and migration direction among multiple sampling locations. Genetics 185:313-326.

4. Boukef, S., McDonald, B. A., Yahyaoui, A., Rezgui, S., and Brunner, P. C. 2012. Frequency of mutations associated with fungicide resistance and population structure of Mycosphaerella graminicola in Tunisia. Eur. J. Plant Pathol. 132:111-122.

5. Cools, H. J., and Fraaije, B. A. 2013. Update on mechanisms of azole resistance in Mycosphaerella graminicola and implications for future control Pest Manage. Sci. 69:150-155.

6. Couleaud, G., Maumene, C., Walker, A. S., and Leroux, P. 2009. Réseau performance: une sixième année de diagnostic de la résistance de Septoria tritici aux principaux fongicides utilisés en France. Pages 640-659 in: Proc. 9th Int. Conf. Plant Dis. AFPP, Tours, France.

7. Drabešová, J., Ryšánek, P., Brunner, P., McDonald, B. A., and Croll, D 2013. Population genetic structure of Mycosphaerella graminicola and quinone outside inhibitor (QoI) resistance in the Czech Republic. Eur. J. Plant Pathol. 135:211-224

8. Estep, L. K., Zala, M., Anderson, N. P., Sackett, K. E., Flowers, M. D., McDonald, B. A., and Mundt, C. 2013. First report of resistance to QoI fungicides in North American populations of Zymoseptoria tritici, causal agent of Septoria tritici blotch of wheat. Plant Dis. 97:1511.

9. Excoffier, L., and Lischer, H. E. L. 2010. Arlequin suite ver. 3.5: a new series of programs to perform population genetics analyses under Linux and Windows. Mol. Ecol. Resour. 10:564-567.

10. Ezzahiri, B. 2010. Maladies fongiques foliaires du blé. Agric. Maghreb 41:66-74

11. Fraaije, B. A., Cools, H. J., Fountaine, J., Lovell, D. J., Motteram, J., West, J. S., and Lucas, J. A. 2005. Role of ascospores in further spread of QoI-resistant cytochrome b alleles (G143A) in field populations of Mycosphaerella graminicola. Phytopathology 95:933-941.

12. Fraaije, B. A., Lucas, J. A., Clark ,W. S., and Burnett, F. J. 2003. QoI resistance development in populations of cereal pathogens in the UK. Pages 689-694 in: Proc. BCPC Int. Congress, Crop Sci. Technol. The British Crop Protection Council, Alton, Hampshire, UK.

13. Gisi, U., Pavic, L., Stanger, C., Hugelshofer, U., and Sierotzki, H. 2005. Dynamics of Mycosphaerella graminicola populations in response to selection by different fungicides. Pages 73-80 in: Modern Fungicides and Antifungal Compounds IV. H. W. Dehne, U. Gisi, K. H. Kuck, P. E. Russell, and H. Lyr, eds. BCPC, Alton, UK.

14. Gisi, U., Sierotzki, H., Cook, A., McCaffery, A., 2002. Mechanisms influencing the evolution of resistance to Qo inhibitor fungicides. Pest Manage. Sci. 58:859-867.

15. Hunter, R., Coker R. R., and Royle, D. J. 1999. The teleomorph stage, Mycosphaerella graminicola, in epidemics of Septoria tritici blotch on winter wheat in UK. Plant Pathol. 48:51-57.

16. Leroux, P., Walker, A. S., Albertini, C., and Gredt, M. 2006. Resistance to fungicides in French populations of Septoria tritici, the causal agent of wheat leaf blotch. Asp. Appl. Biol. 78:153-162.

17. Librado, P., and Rozas, J. 2009. DnaSP v5: a software for comprehensive analysis of DNA polymorphism data. Bioinformatics 25:1451-1452.

18. McCartney, C., Mercer, P. C., Cooke, L. R., and Fraaije, B. A. 2007. Effects of a strobilurin-based spray programme on disease control, green leaf area, 
yield and development of fungicide-resistance in Mycosphaerella graminicola in Northern Ireland. Crop Prot. 26:1272-1280.

19. Ponomarenko, A., Goodwin, S. B., and Kema, G. H. J. 2011. Septoria tritici blotch (STB) of wheat. Plant Health Instructor. Online publication. doi:10.1094/PHI-I-2011-0407-01

20. Saidi, A., Safaie, N., and Palizi, P. 2012. Study on mating types and sensitivity to strobilurin fungicide in fungal wheat pathogen Mycosphaerella graminicola. J. Crop Prot. 1:271-277.

21. Siah, A., Deweer, C., Morand, E., Reignault, P., and Halama, P. 2010. Azoxystrobin resistance of French Mycosphaerella graminicola strains assessed by four in vitro bioassays and by screening of G143A substitution. Crop Prot. 29:737-743.

22. Siah, A., Reignault, P., and Halama, P. Genetic diversity of Mycosphaerella graminicola isolates from a single field. Commun. Agric. Appl. Biol. Sci. In press.

23. Siah, A., Tisserant, B., ElChartouni, L., Duyme, F., Deweer, C., Fichter, C., Sanssené, J., Durand, R., Reignault, P., and Halama, P. 2010. Mating type idiomorphs from a French population of the wheat pathogen Mycosphaerella graminicola: widespread equal distribution and low but distinct levels of molecular polymorphism. Fungal Biol. 114:980-990.

24. Stammler, G., Taher, K., Koch, A., Haber, J., Liebmann, B., Bouagila, A., Yahyaoui, A., and Nasraoui, B. 2012. Sensitivity of Mycosphaerella graminicola isolates from Tunisia to epoxiconazole and pyraclostrobin. Crop
Prot. 34:32-36.

25. Tamura, K., Peterson, D., Peterson, N., Stecher, G., Nei, M., and Kumar, S 2011. MEGA5: molecular evolutionary genetics analysis using maximum likelihood, evolutionary distance, and maximum parsimony methods. Mol. Biol. Evol. 28:2731-2739.

26. Torriani, S. F. F., Brunner, P. C., McDonald, B. A., and Sierotzki, H. 2009. QoI resistance emerged independently at least 4 times in European populations of Mycosphaerella graminicola. Pest Manage. Sci. 65:155-162.

27. Torriani, S. F. F., Goodwin, S. B., Kema, G. H. J., Pandilinan, J. L., and McDonald, B. A. 2008. Intraspecific comparison and annotation of two complete mitochondrial genome sequences from the plant pathogenic fungus Mycosphaerella graminicola. Fungal Genet. Biol. 45:628-637.

28. Ware, S. B. 2006. Pages 101-122 in: Aspects of sexual reproduction in Mycosphaerella species on wheat and barley: genetic studies on specificity, mapping and fungicide resistance. Ph.D. thesis. Wageningen University, Wageningen, The Netherlands.

29. Zhan, J., Kema, G. H. J., and McDonald, B. A. 2004. Evidence for a selective sweep in the mitochondrial genome of Mycosphaerella graminicola. Phytopathology 94:261-267.

30. Zhan, J., Pettway, R. E., and McDonald, B. A. 2003. The global genetic structure of the wheat pathogen Mycosphaerella graminicola is characterized by high nuclear diversity, low mitochondrial diversity, regular recombination, and gene flow. Fungal Genet. Biol. 38:286-297. 